\title{
Conversion to organic farming increases dairy farmers' satisfaction independently of the strategies implemented
}

\author{
Maëlys Bouttes ${ }^{1}$ - Alexandre Bancarel ${ }^{2}$ - Stéphane Doumayzel ${ }^{3}$ - Sandrine Viguié ${ }^{3} \cdot$ Magali San Cristobal $^{4}$. \\ Guillaume Martin ${ }^{1}$
}

Accepted: 2 March 2020 / Published online: 26 March 2020

(C) INRAE and Springer-Verlag France SAS, part of Springer Nature 2020

\begin{abstract}
Farmers in Europe are increasingly converting to organic farming. For farmers, the conversion is an uncertain period that requires multiple changes to comply with organic regulations while not obtaining the organic price for products. Previous research findings highlight the multiple risks of converting to organic farming, but they tend to neglect farmers' satisfaction during the conversion. Our objective was to investigate whether and how farmers could improve their satisfaction during the conversion to organic. We surveyed a sample of 19 dairy farms in Aveyron, France, from 2016 (their last year as conventional) to 2018. We (i) characterised the evolution of dairy farmers' satisfaction and the conversion strategies implemented from the last year of conventional farming up to the end of the conversion to organic, and (ii) identified which conversion strategies improved farmers' satisfaction the most. Satisfaction was assessed by farmers regarding economic, agronomic, livestock-related, and social aspects as well as work conditions. We ran principal component analysis (PCA), hierarchical clustering on principal components (HCPC), and partial least squares (PLS) regression to analyse the data. Our results revealed that all farmers were satisfied after conversion to organic. All observed conversion strategies were oriented towards pasture-based grazing systems and a reduction in land use and herd management intensities. It was not possible to relate specific conversion strategies to specific changes in patterns of satisfaction. This study was the first trying to relate the evolution of farmers' satisfaction to changes in farming practices during the conversion to organic. In showing the strong increase in farmers' satisfaction during the conversion to organic, our results strongly contrast with previous studies that highlighted the multiple risks of converting to organic farming. When supporting farmers considering a conversion, local advisers may consider farmers' objectives and their potential satisfaction regarding their achievements beyond the risks of not obtaining the organic price for products immediately.
\end{abstract}

Keywords Organic agriculture · Dairy farming · Transition · Sustainability · Well-being

\section{Introduction}

Farmers are facing an increasingly turbulent context characterised by volatility in prices of inputs and outputs (Wright 2011) and more frequent extreme climate events

Maëlys Bouttes

maelys.bouttes@gmail.com

1 Université de Toulouse, INRAE, UMR AGIR, F-31320 Castanet-Tolosan, France

2 APABA, F-12026 Rodez, France

3 Chambre of Agriculture of Aveyron, F-12026 Rodez, France

4 Université de Toulouse, INRAE, UMR Dynafor, F-31320 Castanet-Tolosan, France
(IPCC 2013). Since the 2000s and the increased liberalisation of the dairy sector in Europe, strong turbulence in the milk market has challenged many dairy farmers (Brehon 2009). During the previous crisis in 2015-2016, several dairies in France informed farmers that they wanted more organic milk, which would require some farmers to convert to organic. As it was unclear when conventional milk prices would recover, some farmers considered the organic market (Bouttes et al. 2018a). Converting to organic farming requires a period of 18 or 24 months, depending on the dairy farmer's choice (CNAB-INAO 2013). This is challenging for farmers. While not obtaining the organic price for milk, they must comply with organic regulation and implement multiple changes in farming practices, marketing, knowledge exchange networks, and social relations (Lamine and Bellon 2009). This challenge is especially critical in a turbulent context and when farmers 
start with fragile economic situations, as French advisers frequently reported in 2015-2016. Understanding whether and how converting to organic can improve farmers' situations is thus of primary interest to adapt the support provided to farmers during this 18- to 24-month period.

Conversion to organic can be regarded as a specific case of transition, i.e. the process by which the principles governing a system are radically revisited, resulting in changes of both the values of actors and their practices (Hazard et al. 2017). Several studies have analysed farm transitions through the lens of changes in farming practices. Chantre et al. (2015) identified agronomic-coherence phases that reduce input on arable crops throughout a farmer's career. Coquil et al. (2014) analysed transitions to self-sufficient crop-dairy farming and characterised the tools farmers used to make decisions during the transition. García-Martínez et al. (2009) analysed trajectories of mountain cattle farms to identify the mechanisms involved in changing practices. The main limitation of these sources is that they do not relate changes in farmers' practices to changes in farm performances, even though this link is essential to characterise the most suitable transition strategies. Few studies addressed this limitation. Bouttes et al. (2018b) highlighted that farmers' practices influenced trade-offs between economic efficiency and productivity on French organic dairy farms. Falconnier et al. (2015) showed how farming techniques influenced the evolution of farm performances (including yield and labour productivity) in southern Mali. However, these studies assessed farm performance using quantitative indicators defined by experts or researchers that were related mainly to farm economics and productivity and assumed that the higher the performance the better. When assessing transitions, the international literature lacks mixed approaches considering the evolution of farmers' assessment on their situation in relation to changes in farming practices.

In practice, farmers' choices are influenced by trade-offs among a wide range of motivations and objectives, beyond farm economics and productivity, including farmer welfare and self-reliance (Coquil et al. 2014; Bouttes et al. 2018a). Accordingly, farmers may have different sources of satisfaction, i.e. fulfilment of their wishes, expectations, or needs in their professional activities, relating to different dimensions (which criteria, e.g. productivity, workload, or which tradeoff among criteria) and ways to assess them (which indicators quantify each criteria, e.g. work hours, difficulty, or income to assess satisfaction). Only very few studies addressed farmers' satisfaction, and they mostly focused on stable farming systems differing either in size (Besser and Mann 2015) or in the production practices implemented (e.g. organic vs. conventional in Rickson et al. 1999 and Mzoughi 2014). The international literature lacks characterisation of relations between changes in farming practices and farmers' satisfaction along transitions such as a conversion to organic farming. Again, this can best be addressed with mixed approaches combining qualitative data on the evolution of farmers' satisfaction to quantitative data on changes in farming practices.

We investigated the evolution of farmers' satisfaction during the regulatory duration of the conversion to organic farming and the conversion strategies implemented that increased this satisfaction the most with a focus on changes in farming practices. Based on a sample of dairy farms in Aveyron, France, we implemented a mixed approach combining qualitative and quantitative data that successively aimed to (i) characterise the conversion strategies implemented from the last year of conventional farming up to the end of the conversion to organic, (ii) characterise the evolution of dairy farmers' satisfaction, and (iii) identify which conversion strategies improved farmers' satisfaction the most (Fig. 1).

\section{Materials and methods}

\subsection{Choice of satisfaction and conversion strategy variables}

We adopted a mixed approach to select variables illustrating farmers' satisfaction and conversion strategies based on a literature review, participant observation, and exchanges with advisors and farmers in our study territory, the Aveyron Department in South-Western France. In 2015-2016, we did participant observation during three collective farm and factory visits, two organic farmer training sessions, four student interviews with actors in the local dairy sector, and three advice time on the conversion project one-on-one with the adviser and farmer. In 2016, we conducted interviews with the surveyed farmers focused on motivations for converting to organic farming (Bouttes et al. 2018a). In 2017, we organised two focus groups with local advisers and dairy farmers to discuss our choices regarding the studied variables. There was no consensus among farmers on the indicators and

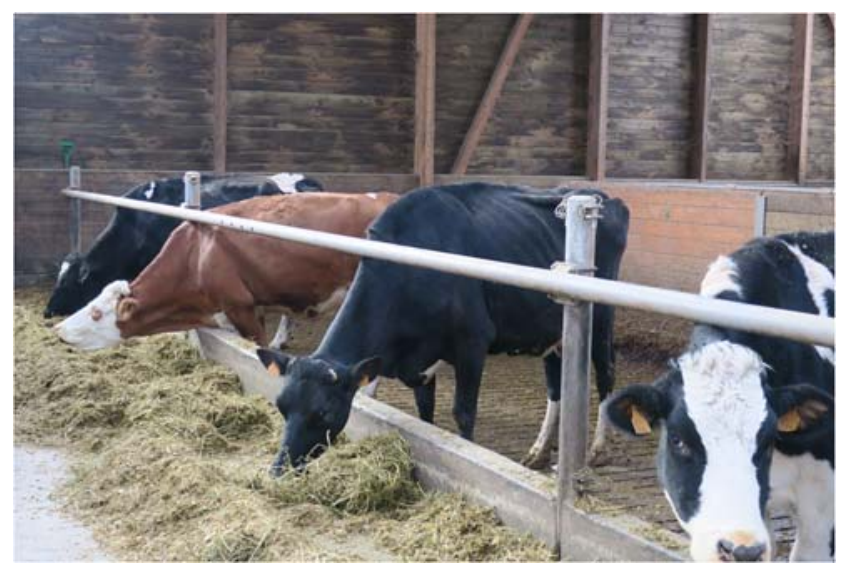

Fig. 1 Picture of a dairy herd in one of the surveyed farms taken during winter 2017-2018, at the end of the conversion to organic farming. Source: Maëlys Bouttes 
reference values best suited to assess farm performances. Thus, we decided to focus on their satisfaction - in the sense fulfilment of their wishes, expectations, or needs - that allows taking smoothing differences in individual preferences and objectives.

We focused on five variables representing farmers' satisfaction:

- Economic status of the farm (e.g. cash flow, debt level, thereafter called "economic")

- Agronomic, i.e. soil and crop conditions (e.g. yields, soil health, thereafter called "agronomic")

- Livestock-related, i.e. herd conditions (e.g. quantity and quality of milk, cow health, thereafter called "livestockrelated")

- Social, i.e. relations with relatives, neighbours, and society (e.g. quality of the exchanges with tourists concerning the farm, thereafter called "social")

- Work conditions subdivided into 6 categories, i.e. the workload and the difficulty of the year-round tasks (e.g. milking cows), the workload and the difficulty of the seasonal tasks (e.g. harvesting corn silage), the free time available to cope with unexpected events (e.g. a tractor failure), and the free time for non-professional life (e.g. holidays) (thereafter called "work conditions")

For variables representing farmers' conversion strategies, we created three groups that illustrated farm structure, herd management intensity, and land use intensity, respectively, following (Bouttes et al. 2018b). These dimensions are often modified during conversion to organic farming. Ultimately, we included 21 conversion strategy variables, composed of 4 farm structure variables, 8 land use intensity variables, and 9 herd management intensity variables:

- Number of dairy cows ("NbCows", livestock units (LU))

- Utilised agricultural area ("UAA", ha)

- UAA accessible for dairy cow grazing ("access", ha/cow)

- Number of dairy cows per worker ("CowWork", LU/ worker)

- Percentage of UAA used to feed livestock ("UAALiv", $\%)$

- Percentage of harvested cereals in the UAA ("cereals", $\%)$

- Percentage of pastures in the UAA used to feed livestock ("pastures", \%)

- Percentage of maize cropping in the UAA used to feed livestock ("maize", \%)

- Percentage of cereal-legume intercrops in the UAA of cereal cropping ("CerLeg", \%)

- Percentage of pastures including legumes in the UAA of pastures ("PastLeg", \%)

- UAA grazed by dairy cows (“UAAGraz”, ha/cow)
- Stocking rate, calculated as the number of dairy cows per ha of the UAA used to feed livestock ("StockingRate", LU/ha)

- Milk production per cow ("Milk", t milk/cow/year)

- Age of heifers at first calving ("1stCalving", months)

- Percentage of heifers in the herd ("heifers", \%)

- Replacement rate, i.e. number of dairy cows in the herd replaced by heifers per year divided by the total number of dairy cows ("replacement", \%)

- Calving interval, i.e. duration between two calvings ("CalvingI", days)

- Calving distribution, i.e. spread of calvings over a year in the herd ("CalvingD", months)

- Amount of concentrates distributed per livestock unit ("Conc", $\mathrm{t} / \mathrm{LU} /$ year)

- Duration of dairy cow grazing ("GrazD”, months)

- Duration of cow feeding without silage or wrapped bales ("NoSilage", months)

\subsection{Case study farms and data collection}

The study was performed from 2016 to 2018 in the Department of Aveyron, a mountainous department in South-Western France with a large range of soil and climatic conditions. This department is the main producer of milk in Southern France with 316,799,000 1 milk (1.3\% of the national production) produced by 50,040 cows ( $1.4 \%$ of the national herd) located in 1041 farms (1.8\% of the French dairy farms) in 2017 (CA Occitanie 2018). The area was selected due to the specific context occurring in 2016. A local dairy decided to increase the locally collected amount of organic milk and started to encourage farmers to convert to organic. Thus, working in Aveyron allowed us to study a group of farmers concurrently engaging in the conversion to organic farming in 2016. Until 2016, about $4.6 \%(n=48)$ of its dairy farms were organic (Agence BIO 2019). In 2016, about 50 conventional farmers decided to convert to organic. Due to the time needed to conduct the survey and to the short time window available for farmers at late winter, we surveyed 19 farms each of the 3 years.

All 19 farms began the conversion in 2016 and implemented a conversion in 18 months, i.e. conversion of land for 1 year and then conversion of the herd for 6 months prior to selling milk with the organic label and price. We selected the 19 farms to capture the diversity in (i) farming systems before conversion, i.e. initially similar or dissimilar to organic practices; (ii) farm sizes (50-145 ha and 35-125 cows); (iii) social situations (age (29-66), gender (13 farms led by men only, 1 farm led by a woman, and 5 farms led by both men and women), individual (6) or collective (13) farm); and (iv) soil and climate conditions (from shallow soil with a Mediterranean climate to rather deep soils with continental climate). We expected that 
the diversity in initial situations would provide sufficient diversity in strategies during conversion to identify those that improve farmers' satisfaction the most. Local organic advisers helped identify and select farmers to ensure the diversity needed. Some farmers also helped to identify others (snowball sampling).

Data were collected through 19 individual face-to-face interviews each year from 2016 to 2018. Each year, we gathered data on the same key aspects of farms and farming systems from the last year of conventional farming (2015) up to the first year of organic farming (2017). These aspects included geographic location, land use, herd structure and management (e.g. feeding, reproduction), and animal production.

In 2018, during the last round of face-to-face interviews, we collected in addition qualitative data on the evolution of farmers' satisfaction. As we wanted to focus on farmers' perceptions of their final situation at the end of the conversion and on the evolution of their situation since conventional in 2015, we asked farmers to answer two questions about each of the five satisfaction variables: (i) How do you feel today? to collect an assessment of the final situation, and (ii) How has your situation changed compared to 2015?, i.e. prior to the conversion to organic farming to collect an assessment of the evolution. To answer the first question, farmers pasted a sticker on a board with seven possible classes: very unsatisfied, unsatisfied, slightly unsatisfied, neutral, slightly satisfied, satisfied, very satisfied. To answer the second question, farmers pasted a sticker on a board with five possible classes: deterioration, slight deterioration, no change, slight improvement, improvement. When several associate farmers were present during the interviews, each pasted a different colour sticker, to represent the diversity of their viewpoints.

\subsection{Statistical analysis}

Our statistical analysis followed three steps to answer our objectives. First, to characterise the evolution of dairy farmers' conversion strategies together with their relative proximities, we performed a principal component analysis (PCA) on the data table where each row is a combination farm by year, the columns being the variables. We removed previously three variables due to high correlation $(>0.8)$ with other variables: "UAALiv" anticorrelated with "cereals", "maize" anti-correlated with "pastures", "access" correlated with "UAAGraz". PCA identified relations among selected variables and projected the farm $\times$ year combinations according to these relations. PCA was performed using the package mixOmics (Lê Cao et al. 2009; González et al. 2011) in R software. To identify clusters of conversion strategies among farms, hierarchical clustering on principal components (HCPC) was performed (Husson et al. 2010) using the initial value (2015) and the variation between 2015 and 2017 for each variable to illustrate the initial strategy and its evolution. Briefly, HCPC combines PCA (deleting components corresponding no noise), followed by hierarchical clustering (Euclidian distance and Ward aggregation method) on the chosen components of the PCA to find the number of clusters, and finally k-means for robust clustering. HCPC was performed using the package FactoMineR (Lê et al. 2008).

Second, to characterise the evolution of dairy farmers' satisfaction, we also performed PCA and HCPC. The data table consisted here in farms in rows, and 5 satisfaction variables. We transformed the stickers' positions collected for the 5 satisfaction variables into grades from -3 to 3 for the final situation in 2018 ( 7 classes) and from -2 to 2 for the evolution between 2015 and 2018 (5 classes). When different sticker positions were selected by the different members of a farm, we took the mean of the different grades. We transformed all these grades on a scale from 0 to 100 to standardise the data for the statistical analysis. PCA was performed using these grades of final situations and evolutions of the five satisfaction variables for each farm. HCPC was performed to identify satisfaction clusters during the conversion.

Third, to identify which conversion strategies improved farmers' satisfaction the most, we calculated a contingency table on the one hand and a partial least squares (PLS) regression on the other hand. We first explored relations between conversion strategy clusters and satisfaction clusters (from both HCPC) using a contingency table. Then, we performed a Pearson chisquare test with simulated $p$ values, due to low counts in the contingency table, in order to test the null hypothesis of independence between strategy clusters and satisfaction clusters. We then performed partial least squares (PLS) regression to explain the evolution of satisfaction variables (the 5 final values and 5 evolutions) by farmers' conversion strategy variables (19 initial values and 19 evolutions) over the 3 years. This model is a slight adaptation of Martin et al. (2017). PLS regression was performed using the package mixOmics (Lê Cao et al. 2009; González et al. 2011) in R software. For PLS regression, we removed the calving interval (initial value and evolution) due to the amount of missing data. We also removed the evolution for calving distribution and stocking rate because they did not vary.

\section{Results and discussion}

\subsection{Farmers' conversion strategies}

We analysed the evolution of farmers' strategies during the conversion to organic farming using PCA to identify relations among variables and distinguish conversion strategies among farms. From the PCA, component 1 (Fig. 2a) explained 29\% of the variance. Principal component 1 opposed two groups of variables:

(i) Duration of grazing (“GrazD”), UAA grazed by dairy cow ("UAAGraz"), percentage of pastures in the UAA 

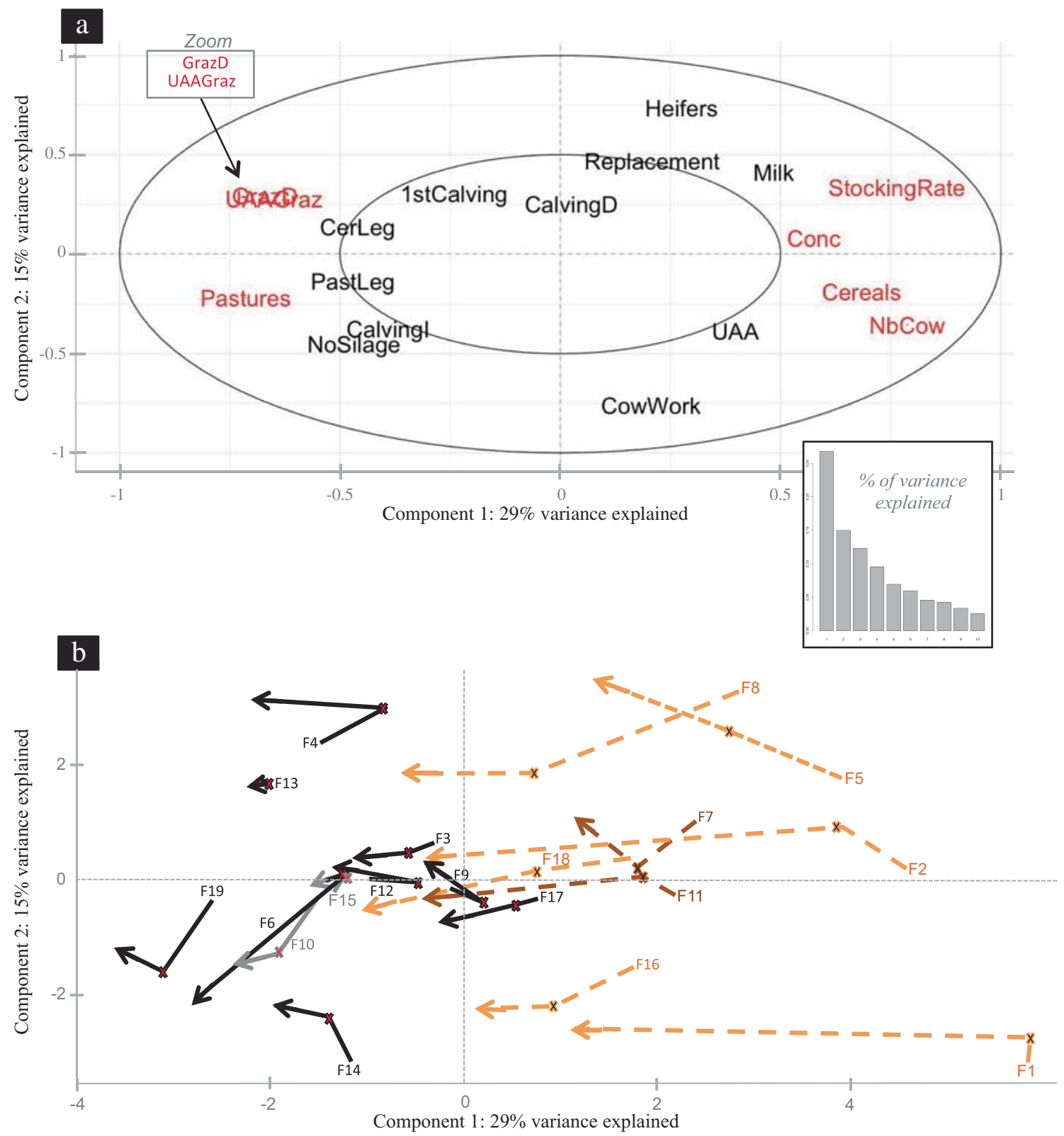

Fig. 2 Principal component analysis (PCA) on the 19 variables of farmers' conversion strategies, showing a relations among variables along principal components (PC) 1 and 2 (explaining 29\% and $15 \%$ of the variance, respectively) and $\mathbf{b}$ individual farm trajectories between 2015 and 2017. Variables contributing the most to PC 1 are displayed in red (a). Each farm (b) is identified by its number. For each farm, the 3 years are connected by an arrow to highlight its trajectory, and the second year (2016) is marked with a cross. The two clusters for two

used to feed livestock ("pastures"), UAA accessible for dairy cows ("access", not on the graph but correlated with "UAAGraz"), and percentage of UAA used to feed livestock ("UAALiv", not on the graph but anti-correlated with "cereals")

(ii) Stocking rate ("StockingRate"), amount of concentrates distributed per animal ("Conc"), percentage of harvested cereals in the UAA ("cereals"), number of cows conversion strategies as revealed by hierarchical clustering on principal components are shown on this graph: conversion strategy 1 (initially similar to organic farming models - solid lines in black or grey, the choice of 2 colours is to distinguish overlapping trajectories) and conversion strategy 2 (having implemented drastic adaptations that focused on pasture-based grazing systems - dashed lines in orange or brown)

("NbCow"), and percentage of maize cropping in the area used to feed livestock ("maize", not on the graph but anti-correlated with "pastures")

Thus, we distinguished between (i) farming systems with a focus on pastures and moderate land use and herd management intensities (Fig. 2a, left side) and (ii) those with a focus 
on cropping and higher land use and herd management intensities (i.e. more concentrates and maize silage fed to cows, higher stocking rate, and more grain cereals cropped, including for cash crops (Fig. 2a, right side)). Linking the projections of individual farms over time (last year of conventional farming, first and second year of conversion; Fig. 2b) revealed their trajectories during conversion. It came out that all conversion strategies observed were oriented towards pasture-based grazing systems and a reduction in land use and herd management intensities (Fig. 2b, all arrows pointing to the left).

The clustering of farms (HCPC) of conversion strategy variables distinguished two clusters: conversion strategy 1 (11 farms) and conversion strategy 2 (8 farms). Table 1 illustrates the initial values before the conversion (2015) and the variations over 2015-2017 for conversion strategy variables highlighted in Fig. 2 a.

The 11 farms following conversion strategy 1 (F3, F4, F6, F9, F10, F12, F13, F14, F15, F17, and F19; Table 1) were most similar to organic farming models when conventional, i.e. pasture-based farming systems with a focus on grazing and moderate land use and herd management intensities. Except for farm F6, they evolved less during the conversion than the farms following conversion strategy 2. The stocking rate was relatively low in 2015 and evolved little in 2017. Even when conventional, these farms had at least the minimum area necessary for dairy cow grazing ( $0.3 \mathrm{ha} / \mathrm{cow}$ for "UAAGraz" according to local advisers). The duration of grazing ("GrazD") was relatively long in 2015 and evolved little by 2017. The percentage of pastures in the area used to feed livestock ("pastures") was higher in 2015 than that of farms from strategy 2 and increased to the detriment of maize cropping ("maize") for the vast majority of these farms in 2017. The amount of concentrates distributed per animal ("Conc") was lower in 2015 than in farms from strategy 2 and decreased or did not evolve. Thus, these farms focused mainly on pastures for grazing cows when conventional and slightly strengthened this strategy during the conversion.

The 8 farms following conversion strategy 2 (F1, F2, F5, F7, F8, F11, F16, and F18; Table 1) were those initially most dissimilar to organic farming models, i.e. higher land use and herd management intensities when conventional than farms following conversion strategy 1 . They also implemented strategies that focused on pasture-based grazing systems but made larger changes during the conversion. The stocking rate was relatively high in 2015 and decreased with the number of cows ("NbCow") until 2017. The accessible area ("access") was lower than that of the other strategies with three farms below the minimum threshold ( $<0.3 \mathrm{ha} / \mathrm{cow})$, and it evolved little. The grazed area ("UAAGraz") was lower in 2015 than that in farms following the other strategies, and it increased or did not evolve. The duration of grazing (“GrazD”) increased or did not evolve as well. Accordingly, the percentage of pastures in the area used to feed livestock ("pastures") increased until 2017 to the detriment of cereal and maize cropping ("cereals" and "maize", respectively). The amount of concentrates distributed per animal ("Conc") decreased due to the large change in strategy to using pastures to feed livestock at grazing during the conversion. These farms were fairly intensive when conventional and increased grazing during the conversion to organic farming.

Only one study (Bouttes et al. 2019) had previously characterised the evolution of farming practices during a conversion to organic in dairy farming based on a 5-year survey of dairy farms in Brittany, France, from their last year of conventional farming up to 2 years following the conversion. In the present study like in the previous one, all the conversion strategies observed were oriented towards pasture-based grazing systems and a reduction in land use and herd management intensities; however, the initial situation and the degree of change during the conversion revealed two strategies. Those results agree with Bouttes et al. (2019), who identified these two types of strategies. The farms initially dissimilar to organic farming models from the point of view of farming practices transformed their farming systems to increase autonomy in animal feeding and other aspects (e.g. decision-making), in a way similar to that of conventional dairy farms transitioning towards autonomy (Coquil et al. 2014; Lebacq et al. 2015). Organic inputs are far more expensive than conventional inputs. Thus, the changes implemented aim to rebalance the potential productivity of the land and herd feed requirements so that farmers can recover room to manoeuvre. This finding also confirms that when seeking to develop their farm's adaptive capacity, farmers strive for autonomy (Darnhofer, 2010) by reducing as much as possible their reliance on external resources.

Our study considered only the regulatory duration of the conversion. For farmers, changes are implemented over a longer period of time (Lamine and Bellon 2009). It might be relevant to study the evolution of those strategies throughout a farmer's entire career (Bellon et al. 2007), thus including the farmer's previous practices (Lamine 2011) and the changes implemented after the regulatory duration of conversion. Such longer studies may allow characterising more comprehensively how farmers develop their experiential learning and progressively move away from the recommendations they receive to take initiatives and change in accordance with their own goals. Chantre et al. (2015) developed the concept of agronomic-coherence phases to characterise transitions towards decreased inputs on field crops throughout a farmer's career. Combining this long-term vision with our year-to-year approach could inform short- to long-term pathways of changes on farms converting to organic. This could help advisors and policy-makers to adjust the support (guidelines, incentives, etc.) provided to farmers during the transition. 


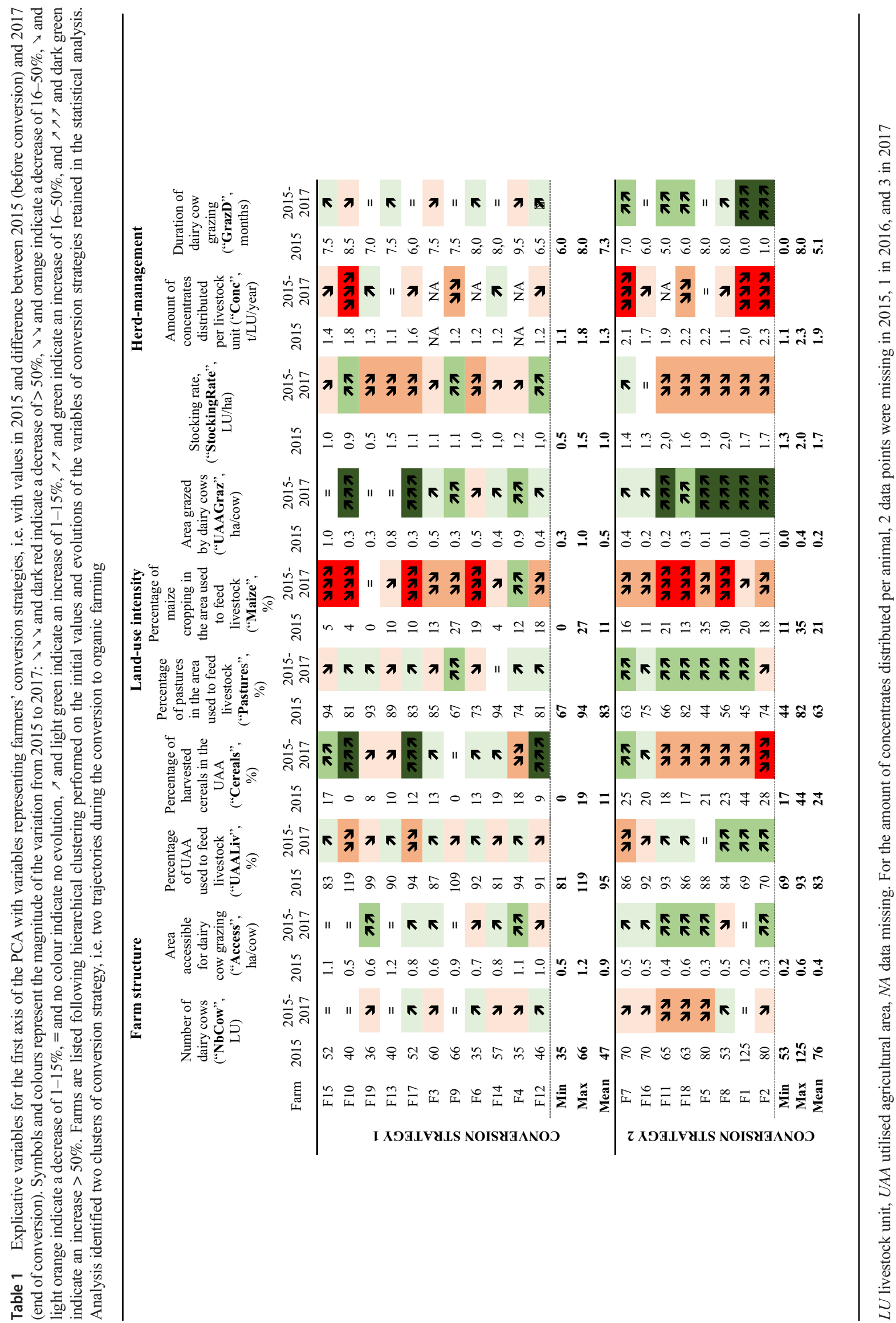




\subsection{Evolution of farmers' satisfaction during conversion}

We analysed the evolution of and final farmers' satisfaction during the conversion to organic farming using PCA and HCPC to identify relations among variables and distinguish satisfaction clusters among farms. Farmers were mostly satisfied across all five satisfaction variables at the end of the conversion and generally considered that their situation had improved (Fig. 3). Farmers had a positive or neutral evaluation of the evolution and final level of their economic and social situations. Only $6 \%$ of the evaluations were lower than neutral (i.e. grades $<50$; hatched cells on the lines evolution of Fig. 3) and concerned three of the five satisfaction variables: agronomic (evolution or final level), livestock-related (evolution), and work conditions (evolution or final level). In total, $84 \%$ of evaluations were neutral or higher (white to black cells on the lines evolution of Fig. 3): $41 \%$ had a grade of 100 and only $19 \%$ were neutral (i.e. grade of 50 ). Only $4 \%$ of evaluations had grades of $26-49$, while $2 \%$ had a grade of 25 (the minimum grade). No farms had only negative or neutral evaluations. However, 9 farms evaluated either a final level or evolution negatively, while 1 farm evaluated both of them negatively (and in the same satisfaction variable: agronomic). No farms had grades of 100 in all satisfaction variables, but among the 9 farms with only neutral or higher evaluations, only 3 farms had higher than neutral evaluations in all satisfaction variables.

Components 1 and 2 of the PCA of satisfaction variables (final values and evolution) (not shown) explained 27\% and $25 \%$ of variance, respectively, which helped explain relations among the variables. Along component 1 , final levels of agronomic and social satisfaction and their evolution were positively correlated. The final level of economic satisfaction lay between components 1 and 2, independent of other variables. The evolution of livestock-related satisfaction lay along component 2 and was also independent of other variables.

The clustering (HCPC based on the previous PCA) distinguished three clusters (Fig. 3). The first satisfaction cluster included 6 farms (F3, F5, F10, F12, F13, and F16). This cluster was mainly characterised by (i) high final economic satisfaction (all grades of 100) influenced by a general increase in economic satisfaction (grades of 50-100; mean =92) and (ii) decrease (for 2 farms) or no change in livestock-related satisfaction (grades of $25-50$; mean $=42$ ), resulting in a final livestock-related satisfaction of 50-100 (mean $=75)$. The farmers explained that their high grades for final economic satisfaction reflected the additional subsidies obtained during the conversion (from the dairy and the government) and the satisfaction of their first payment for milk at the organic price. They also mentioned that production costs decreased once they became organic due to, among other things, climate
Fig. 3 Hierarchical clustering on principal components of farmers' satisfaction (graded from 0 to 100) based on the final level and evolution of five satisfaction variables during conversion to organic farming, revealing three clusters of farms (F1-F19). Satisfaction variables in bold were those that were influential in distinguishing the clusters.

Blocks of farms $\times$ variables that characterise a given cluster are outlined in black

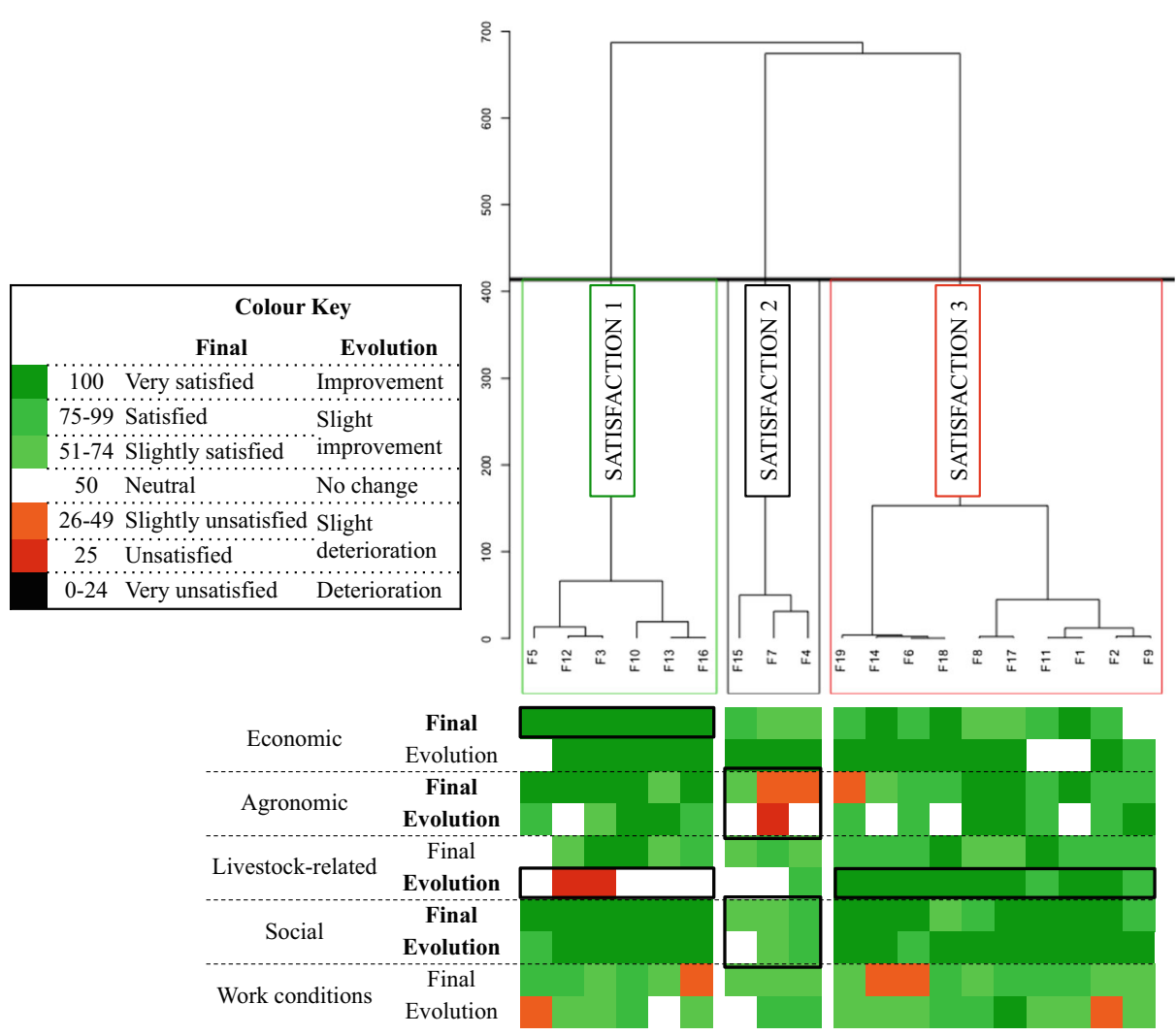


conditions favourable for grazing during the last year of their conversion.

All the farmers except one were unsatisfied before the conversion and perceived that their economic situation had improved greatly. In contrast, these farmers did not perceive an improvement in their livestock-related satisfaction and hoped that the situation would improve in the future. Some experienced a large decrease in the quantity and quality of milk during their first few organic winters and were still looking for solutions. Nervousness and stress were among the words used by farmers commenting their situation, as problems of milk quality and quantity indicate failure and may impact farm profitability.

The second satisfaction cluster included 3 farms (F4, F7, and F15). This cluster had lower grades for the final level and evolution of agronomic and social satisfactions than the other clusters. Agronomic satisfaction decreased or did not change, depending on the farm $(25-50$; mean $=42)$, and had mostly low final grades $(33-67$; mean $=44)$. Social satisfaction increased or did not change $(50-75$; mean $=63)$, with relatively high final grades $(67-83$; mean $=72)$. For agronomic satisfaction, the farmers had diverse experiences during the conversion. For example, on one farm, the farmer set up no-till trials while converting to organic, and the results were unsatisfactory. Another farmer was disappointed with the cereal and pasture yields. Regarding social satisfaction, two farmers provided ambivalent answers: the social situation in the nonagricultural environment improved, especially with other organic farmers, but interactions with conventional farmers deteriorated. Farmers mentioned the importance of solidarity with neighbours, organic or not, when they encounter risks and/or perform collective field work, such as harvesting silage maize. They were satisfied with the increase of positive interactions with people outside the farming community, which are a great emotional support. The remaining farmers in this cluster evaluated their situation positively, with no changes.

The third satisfaction cluster included 10 farms (F1, F2, F6, F8, F9, F11, F14, F17, F18, and F19) and was mainly driven by livestock-related satisfaction that increased, with grades ranging from 75 to $100($ mean $=95)$, and had high final levels $(67-100 ;$ mean $=83)$. The farmers related this improvement to the perception of fewer animal health problems and higher milk quality, although some farmers remained anxious about the latter. Some farmers related this improvement to the decrease in the number of cows and the increase in the amount of grazing in their diet. Due to these changes, farmers felt that they were more attentive to individual cow issues and were accordingly more proactive and reactive.

From the main body of the literature, we expected farmers to have less economic and agronomic satisfaction after the conversion to organic (MacRae et al. 1990; Lamine and Bellon 2009). Several studies indicated that conversion to organic farming might be an economically or/and technically difficult time for farmers, which could imply a higher sensitivity to risks. Padel (2001) argues that the conversion is often costly. Other authors indicate an "organic transition effect" (Liebhardt et al. 1989; MacRae et al. 1990); i.e. technical and economic performances decrease for the first few years after conversion, but after 3 years or more, soil quality and biological activity improve and lead to an increase in yields. Martini et al. (2004) suggest that the learning required to develop the skills involved in organic farming could result in more technical failures in the first few years after conversion.

These studies highlight uncertainties in the agronomic and therefore economic performances during conversion. Agroecosystem responses to changes in practices are unknown for farmers, as is the time required for the agroecosystem to reach a new equilibrium. Thus, farmers might experience technical failures and/or an uncertain and stressful period. These emotional difficulties would result in a reduced ability to absorb and adapt to changes, i.e. increased vulnerability. In our study, farmers were economically satisfied at the end of the conversion and were mostly satisfied with the agronomic performances. Among economic perceptions, many farmers mentioned the reduction in production costs, the support provided by conversion subsidies (from the European Union and the local dairy), and their satisfaction with the first payment for milk at the organic price.

This is the first study characterising the evolution of farmers' satisfaction during a conversion to organic. Most farmers were more satisfied at the end of their conversion than when conventional. Although our sample size is limited, our results agree with those of Mzoughi (2014), who, in a comparative study, demonstrated that farmers in the process of conversion were more satisfied than conventional farmers. All farmers interviewed in our study evaluated positively the evolutions and final levels of their economic and social satisfactions. This echoes the results of Mzoughi (2014) who highlighted the importance of two aspects to increase satisfaction: (i) financial compensation, i.e. the profitability during the conversion; and (ii) social compensation, i.e. social recognition by society and peers. Social satisfaction increased for 18 out of the 19 farmers, with the remaining farmer indicating no change, confirming earlier findings that showed how social recognition was an important motivation for converting to organic farming (Bouttes et al. 2018a; Xu et al. 2018). Social satisfaction may also have increased along with peerto-peer exchanges on farmers' practices that farmers highly valued (Bouttes et al. 2018a). Those exchanges stimulate farmers' experiential learning and develop their adaptive capacity (Darnhofer, 2010). We did not assess those learning processes, but in future studies, it would be relevant to assess how they influenced the evolution of farmers' satisfaction.

Our method focuses on farmers' perceptions of satisfaction through five satisfaction variables. We considered all five variables together to distinguish patterns in satisfaction, which is 
relevant for discussing the trade-offs between satisfaction variables. However, this analysis cannot identify the overall reasons for satisfaction and dissatisfaction in each variable. Further qualitative studies should be pursued to better understand the reasons that underlie the positive and negative evaluations farmers expressed. We assumed that all five variables contributed to overall satisfaction to the same degree, but farmers might have different perceptions, with different weights assigned to each variable. A method that considers individual prioritisation, i.e. which variable is the most important to each farmer, could help adapt the support provided to a conversion project, according to the farmer's objectives. Also, to evaluate satisfaction, our method entailed asking farmers to self-report their perceptions of satisfaction, as in Mzoughi (2014). This approach has several limitations (Conceição and Bandura 2008). Circumstances and individuals' emotional states at the time of the discussion might influence their evaluation greatly. This approach could be supplemented with other methods, such as an evaluation several times a year (e.g. each month) over a longer period.

\subsection{Relations between farmers' conversion strategies and satisfaction}

The contingency table between the satisfaction and conversion strategy clusters (Table 2) was used as the basis for a chi-square test that yielded a $p$ value of 0.8 . Thus, statistically we cannot conclude that a given conversion strategy results in a specific pattern of satisfaction. Instead, it seems possible to reach a given pattern of satisfaction from different trajectories although. And the worst evolutions (deterioration or no change) of farmers' satisfaction in the sample were observed in either groups of conversion strategies depending on the satisfaction variable considered: satisfaction regarding economic (F1, F5, F11), agronomic (F7), and work conditions (F2, F5) for conversion strategy 2, and livestock-related (F3, F12) and social (F15) satisfaction for conversion strategy 1. We further supported this conclusion with the PLS analysis, which helped to explain the satisfaction variables and the strategy variables without considering the previously established clusters. The PLS regression (not shown) explained only the evolutions of economic and agronomic satisfaction but not those of the other satisfaction variables. A single conversion strategy could not explain the evolutions of these two satisfaction variables.

This was the first study that tried to relate the evolution of farmers' satisfaction during the regulatory duration of the conversion to organic farming and the conversion strategies implemented with a focus on changes in farming practices. Overall, our results show that transitioning to pasture-based grazing systems and reducing land use and herd management intensities are satisfactory answers against the increasingly uncertain and changing agricultural production context, as already shown in the organic (Bouttes et al. 2019) and conventional sectors (Coquil et al. 2014; Lebacq et al. 2015). However, due to the similarity in the farmers' strategies observed at the end of the conversion, with all farms converging towards pasture-based grazing systems and a reduction in land use and herd management intensities, our analysis did not distinguish relations between the strategies and satisfaction clusters identified; i.e. different strategies can result in the same satisfaction cluster. One reason could lie in their engagement in the conversion. By converting to organic, farmers become part of a new community of practice and thereby increase their feeling of security and control over the situation (Bouttes et al. 2018a). This emotional and psychological change can influence their satisfaction to a higher extent than changes in farming practices do as illustrated by this farmer (F11) saying: "I have rediscovered the pleasure of sharing experiences. I rediscovered my profession, questioned what I was doing. And today I feel better."

The methodology of face-to-face interviews with farmers over the 3 years allowed us to collect data on conversion strategies and satisfaction. This approach is relevant to better capture the dynamics of farmers' satisfaction and to understand their conversion strategies. However, it is a time-consuming process that limits the number of farms surveyed. To overcome this limitation, we discussed these results with farmers and advisors in other territories during two conferences in autumn 2018 ("Auvergne-Rhônes-Alpes" and "Brittany" regions). Our findings generally matched their experiences. Still, further research with interviews or questionnaires is necessary to challenge our results.

Table 2 Contingency table between satisfaction clusters and conversion strategy clusters, showing the farms in each cluster identified by partial least squares regression

\begin{tabular}{|c|c|c|c|}
\hline & $\begin{array}{l}\text { Satisfaction } 1 \\
6 \text { farms }\end{array}$ & $\begin{array}{l}\text { Satisfaction } 2 \\
3 \text { farms }\end{array}$ & $\begin{array}{l}\text { Satisfaction } 3 \\
10 \text { farms }\end{array}$ \\
\hline $\begin{array}{l}\text { Conversion strategy } 1 \\
11 \text { farms }\end{array}$ & 4 farms: F3, F10, F12, F13 & 2 farms: F4, F15 & 5 farms: F6, F9, F14, F17, F19 \\
\hline $\begin{array}{l}\text { Conversion strategy } 2 \\
8 \text { farms }\end{array}$ & 2 farms: F5, F16 & 1 farm: F7 & 5 farms: F1, F2, F8, F11, F18 \\
\hline
\end{tabular}




\section{Conclusion}

We investigated whether and how farmers could improve their satisfaction during the conversion to organic. All conversion strategies focused on pasture-based grazing systems and a reduction in land use and herd management intensities. We identified two patterns of conversion strategies: (i) systems similar to organic farming models when conventional that changed little during conversion, and (ii) systems initially dissimilar to organic farming models that implemented conversion strategies that increased grazing, with major changes during the conversion. Due to high similarity in the endpoint and to very high levels of satisfaction for all farmers following the conversion to organic, we cannot conclude, however, that a given conversion strategy leads to a specific pattern of satisfaction. This study was relatively exploratory and, as it contrasts with previous research findings highlighting the multiple risks of converting to organic farming, it requires further analysis of relations between the evolution of farmers' strategies and their satisfaction during the conversion to organic farming. Nevertheless, it suggests that when supporting farmers considering a conversion, local advisers may consider farmers' objectives and their potential satisfaction regarding their achievements beyond the risks of not obtaining the organic price for products immediately.

Acknowledgments The authors wish to thank the farmers who generously gave their time for the interviews. We thank Marie Destruel for her help in organising the data and performing the interviews in the second year. We thank Laurent Bedoussac, Michel Duru, Julien Quenon, Augustine Perrin, and Magali Willaume for their participation in the two writing workshops we organised. We thank Jean-Christophe Vidal, Claudine Murat, Stéphane Doumayzel, Sandrine Viguié, Alexandre Bancarel, Johan-Kévin Galtier, Maxime Vial, Christian Issaly, Francis Rigal, Alexandre Saurel, Lucie Bastide, Pascal Massol, and Vincent Savy for their participation in the focus groups.

Funding information This study was funded by INRA and the MidiPyrénées region as part of the ATARI project and Maëlys Bouttes's Ph.D. project, and by the French ANR Agrobiosphère program as part of the TATABOX project (ANR-13-AGRO-0006).

Compliance with ethical standards The authors declare that they have no conflict of interest.

\section{References}

Agence BIO (2019) Les chiffres clés - Agence Bio. https://www. agencebio.org/vos-outils/les-chiffres-cles/. Accessed 31 July 2019

Bellon S, Navarrete M, Fauriel J, et al (2007) Converting to organic horticulture as socio-technical trajectories. XXII ESRS Congress, Wageningen, Netherlands, 2007/08/20-24

Besser T, Mann S (2015) Which farm characteristics influence work satisfaction? An analysis of two agricultural systems. Agric Syst 141:107-112. https://doi.org/10.1016/J.AGSY.2015.10.003
Bouttes M, Darnhofer I, Martin G (2018a) Converting to organic farming as a way to enhance adaptive capacity. Org Agric 9:235-247. https:// doi.org/10.1007/s13165-018-0225-y

Bouttes M, San Cristobal M, Martin G (2018b) Vulnerability to climatic and economic variability is mainly driven by farmers' practices on French organic dairy farms. Eur J Agron 94:89-97. https://doi.org/ 10.1016/j.eja.2018.01.013

Bouttes M, Bize N, Maréchal G, Michel G, Cristobal MS, Martin G (2019) Conversion to organic farming decreases the vulnerability of dairy farms. Agron Sustain Dev 39:19-11. https://doi.org/10. 1007/s13593-019-0565-3

Brehon N-J (2009) L'Europe et la crise du lait : quelles régulations pour le secteur laitier?

CA Occitanie (2018) L'élevage bovin lait

Chantre E, Cerf M, Le Bail M (2015) Transitional pathways towards input reduction on French field crop farms. Int J Agric Sustain 13: 69-86. https://doi.org/10.1080/14735903.2014.945316

CNAB-INAO (2013) GUIDE de LECTURE du RCE n 834/2007 et du RCE n 889/2008

Conceição P, Bandura R (2008) Measuring subjective wellbeing: a summary review of the literature. United Nations Dev Program, p 1-35

Coquil X, Béguin P, Dedieu B (2014) Transition to self-sufficient mixed crop-dairy farming systems. Renew Agric Food Syst 29:195-205. https://doi.org/10.1017/S1742170513000458

Darnhofer I (2010) Strategies of family farms to strengthen their resilience. Environ Policy Gov 20:212-222. https://doi.org/10.1002/eet. 547

Falconnier GN, Descheemaeker K, Van Mourik TA et al (2015) Understanding farm trajectories and development pathways: two decades of change in southern Mali. Agric Syst 139:210-222. https://doi.org/10.1016/j.agsy.2015.07.005

García-Martínez A, Olaizola A, Bernués A (2009) Trajectories of evolution and drivers of change in European mountain cattle farming systems. Animal 3:152-165. https://doi.org/10.1017/ S1751731108003297

González I, Lê Cao K-A, Déjean S (2011) mixOmics: omics data integration project. http://www.mixomics.org

Hazard L, Magrini MB., Martin G. (2017) Agroecological transition (definition). Available at: https://dicoagroecologie.fr/en/ encyclopedia/agroecological-transition/

Husson F, Josse J, Pagès J (2010) Principal component methods - hierarchical clustering - partitional clustering: why would we need to choose for visualizing data? Tech Rep 1-17. http://factominer.free. $\mathrm{fr} / \mathrm{docs} / \mathrm{HCPC}$ husson josse.pdf

IPCC (2013) Climate change 2013: the physical science basis. Contribution of Working Group I to the Fifth Assessment Report of the Intergovernmental Panel on Climate Change. In: Stocker TF, Qin D, Plattner G-K, Tignor M, Allen SK, Boschung J, Nauels A, Xia Y, Bex V (eds). Cambridge, United Kingdom and New York, NY, USA

Lamine C (2011) Transition pathways towards a robust ecologization of agriculture and the need for system redesign. Cases from organic farming and IPM. J Rural Stud 27:209-219. https://doi.org/10.1016/ j.jrurstud.2011.02.001

Lamine C, Bellon S (2009) Conversion to organic farming: a multidimensional research object at the crossroads of agricultural and social sciences. A review. Agron Sustain Dev 29:97-112. https://doi.org/ 10.1051/agro:2008007

Lê Cao K-A, González I, Déjean S (2009) integrOmics: an R package to unravel relationships between two omics datasets. Bioinformatics 25:2855-2856. https://doi.org/10.1093/bioinformatics/btp515

Lê S, Josse J, Husson F (2008) FactoMineR: an R package for multivariate analysis. J Stat Softw 25:1-18. https://doi.org/10.1016/j.envint. 2008.06.007

Lebacq T, Baret PV, Stilmant D (2015) Role of input self-sufficiency in the economic and environmental sustainability of specialised dairy 
farms. Animal 9:544-552. https://doi.org/10.1017/ S1751731114002845

Liebhardt WC, Andrews RW, Culik MN et al (1989) Crop production during conversion from conventional to low-input methods. Agron J 81:150-159. https://doi.org/10.2134/agronj1989. $00021962008100020003 x$

MacRae RJ, Hill SB, Mehuys GR, Henning J (1990) Farm-scale agronomic and economic conversion from conventional to sustainable agriculture. Adv Agron 43:155-198. https://doi.org/10.1016/S00652113(08)60478-2

Martin G, Magne M-A, Cristobal MS (2017) An integrated method to analyze farm vulnerability to climatic and economic variability according to farm configurations and farmers' adaptations. Front Plant Sci. https://doi.org/10.3389/fpls.2017.01483

Martini EA, Buyer JS, Bryant DC et al (2004) Yield increases during the organic transition: improving soil quality or increasing experience? Field Crop Res 86:255-266. https://doi.org/10.1016/j.fcr.2003.09.002

Mzoughi N (2014) Do organic farmers feel happier than conventional ones? An exploratory analysis. Ecol Econ 103:38-43. https://doi. org/10.1016/j.ecolecon.2014.04.015
Padel S (2001) Conversion to organic farming: a typical example of the diffusion of an innovation? Sociol Rural 41:40-61. https://doi.org/ $10.1111 / 1467-9523.00169$

Rickson RE, Saffigna P, Sanders R (1999) Farm work satisfaction and acceptance of sustainability goals by Australian organic and conventional farmers' Roy E. Rickson, Paul Saffigna, and Richard Sanders 64:266-283

Wright BD (2011) The economics of grain price volatility. Appl Econ Perspect Policy 33:32-58. https://doi.org/10.1093/aepp/ppq033

$\mathrm{Xu} \mathrm{Q}$, Huet S, Poix C et al (2018) Why do farmers not convert to organic farming ? Modeling conversion to organic farming as a major change. Nat Resour Model 31:e12171. https://doi.org/10.1111/ nrm. 12171

Publisher's note Springer Nature remains neutral with regard to jurisdictional claims in published maps and institutional affiliations. 